Tohoku J. exp. Med., 1980, 132, 103-109

\title{
Urinary Keratan Sulfate of Morquio's Disease
}

\author{
Osamu Namiki, Masaaki Masubuchi, Hiromichi Toyoshima, \\ Masahiko Endo* and Zensaku Yosizawa* \\ Department of Orthopaedic Surgery, Tokyo Women's Medical \\ College, Tokyo 162, and *Department of Biochemistry, Tohoku \\ University School of Medicine, Sendai 980
}

\begin{abstract}
Namiki, O., Masubuchi, M., Toyoshima, H., Endo, M. and Yosizawa, Z. Urinary Keratan Sulfate of Morquio's Disease. Tohoku J. exp. Med., 1980, 132 (1), 103-109 — To elucidate precise chemical nature of urinary keratan sulfate (KS) of Morquio's disease, crude glycosaminoglycans (GAG) were separated from 24-hr urines of 3 patients with Morquio's disease and from pooled urine of a healthy boy, using cetylpyridinium chloride. KS fractions were then separated from the crude GAG after removal of other GAG and acidic glycopeptide by successive digestion with testicular hyaluronidase and chondroitinase $\mathrm{ABC}$, and by nitrous acid treatment, followed by Dowex 1 column chromatography. The distribution of KS in several fractions (1.5 M Fr-5.0 M Fr) obtained by Dowex 1 column chromatography suggested polydispersity of urinary KS. The relative amounts $(\mu \mathrm{g} / 24-\mathrm{hr}$ urine $/ \mathrm{kg}$ body weight) of the KS fractions excreted into Morquio's urine were 52-63 times as much as that excreted into normal urine. The KS fractions contained galactose, glucosamine and sulfate as the major constituents, together with fairly amounts of galactosamine and sialic acid, and small amounts of mannose, $\mathrm{L}$-fucose and glucose. The KS fractions resembled sulfated glycopeptide with respect to the sugar composition. The contents of sulfate and sialic acid in each KS fraction from Morquio's urine were higher than those in the corresponding one from normal urine, whereas opposite was the case for the ratio of glucosamine to galactosamine. The sulfate contents in the KS fractions from Morquio's urine indicated that the patient excreted oversulfated KS into urine. The chemical compositions of the KS fractions from Morquio's urine suggest that the sulfatase specific for 6 -sulfate linked to sugars with the galactose configuration may act in a early step of the catabolism of oversulfated KS in the normal tissues. Keratan sulfate; Morquio's disease; urinary keratan sulfate
\end{abstract}

Morquio's disease has been known to be a mucopolysaccharidosis with a heritable disorder in the catabolism of keratan sulfate (KS) and chondroitin 6-sulfate and the patient excretes large amounts of these GAG into urine (McKusick 1972; Dorfman and Matalon 1976). The enzyme defect in this disease was reported to be a sulfatase specific for the 6-sulfate linked to sugars with the galactose configuration such as $\mathrm{N}$-acetylgalactosamine 6-sulfate and galactose 6-sulfate (Horwitz and

Received for publication, July 31, 1979.

Present address: Dr. M. Endo, Department of Biochemistry, Hirosaki University School of Medicine, Hirosaki 036.

Abbreviations: KS, keratan sulfate; GAG, glycosaminoglycans; AGP, acidic glycopeptide. 
Dorfman 1978). However, urinary KS of Morquio's disease has not been characterized satisfactorily.

To elucidate precise chemical nature of urinary KS of Morquio's disease, a comparative study was performed on the KS fractions isolated from urines of the patients suffering from this disease with those from normal human urine. This paper reports the results of the study.

\section{Materials and Methods}

Materials. Standard preparations of GAG were supplied by Dr. M.B. Mathews. Bovine testicular hyaluronidase and chondroitinase $A B C$ were purchased from Miles Laboratories, Elkhard, Indiana, and Seikagaku Kogyo Co., Tokyo, respoctively. Cellulose acetate membrane (Separax), Toluidine blue and Alcian blue 8GS were the same as reported previously (Endo et al. 1979). Other materials were commerical products.

Urines were separately collected from 3 patients with Morquio's disease without any dietary restriction, and pooled control urine (20 liters) from a healthy body as described in a previous paper (Endo et al. 1974a).

Separation of crude $G A G$ from urine. Crude GAG were separated from each urine by the procedures, using cetylpyridinium chloride, as reported previously (Endo et al. 1974b).

Fractionation of crude $G A G$ with ethanol. The above crude GAG were fractionated with ethanol by a modification of the method of Meyer et al. (1956). The crude GAG (200 $\mathrm{mg}$ ) were dissolved in $10 \mathrm{ml}$ of $0.5 \mathrm{M}$ acetic acid containing $5 \%$ calcium acetate. Ethanol was added to the solution to a final concentration of $40 \%$ with stirring at room temperature, and the mixture was left to stard for $1 \mathrm{hr}$ at room temperature. The precipitate was removed by centrifugation. Ethanol was then added to the supernatant to a final concentration of $80 \%$ as above. The precipitate was collected by centrifugation, dissolved in water, dialyzed and lyophilized, yielding ethanol fraction.

Enzymatic digestion and nitrous acid treatment of the ethanol fraction. The above ethanol fraction was dissolved in $0.02 \mathrm{M}$ acetate buffer (pH 5.0) containing $0.15 \mathrm{M} \mathrm{NaCl}$. Testicular hyaluronidase (10 mg per $100 \mathrm{mg}$ of the sample) and a small volume of toluene were added to the solution, and the mixture was incubated for $12 \mathrm{hr}$ at $37^{\circ} \mathrm{C}$ by the procedure of Rapport et al. (1951). After the incubation, 4 volumes of ethanol saturated with $\mathrm{NaCl}$ were added to the incubation mixture, which was then cooled in ice-water. The precipitate was collected by centrifugation, dissolved in the buffer of Yamagata et al. (1968), followed by digestion with chondroitinase $\mathrm{ABC}$ ( 2 units) according to the procedure of Yamagata et al. (1968). The incubation mixture was then treated by the procedures as reported previously (Endo et al. 1980b). The substances remained after chondroitinase ABC digestion were subjected to nitrous acid treatment to remove heparan sulfate by the procedure of Endo et al. (1980b), yielding a fraction containing KS and acidic glycopeptide (AGP).

Dowex 1 column chromatography. The above fraction containing KS and AGP was fractionated by Dowex 1 column chromatography according to the procedure reported previously (Endo and Yosizawa 1973). The fractions eluted with $\mathrm{H}_{2} \mathrm{O}, 0.5 \mathrm{M}_{,} \ldots, 4.0$ $\mathrm{M}$ and $5.0 \mathrm{M} \mathrm{NaCl}$ were designated as $\mathrm{H}_{2} \mathrm{O} \mathrm{Fr}, 0.5 \mathrm{M} \mathrm{Fr}, \ldots, 4.0 \mathrm{M}$ Fr and $5.0 \mathrm{M} \mathrm{Fr}$, respectively.

Other methods. Electrophoresis on cellulose acetate membrane (Separax) was carried out as reported previously (Endo and Yosizawa 1975), staining with Toluidine blue $30.05 \%$ in $80 \%$ ethanol) and/or Alcian blue $(0.05 \%$ in $80 \%$ ethanol). Paper chromatography was performed as described previously (Endo et al. 1980a).

Determination of constituents. Quantitative determination of total hexose (Dubois et al. 1956), total hexosamine (Blix 1948) with an acid hydrolyzate $\left(4 \mathrm{M} \mathrm{HCl}, 8 \mathrm{hr}, 100^{\circ} \mathrm{C}\right.$ ), 
hexuronic acid (Bitter and Muir 1962), sulfate (Antonopoulos 1962) and sialic acid (Warren 1959) were performed by the methods in the cited references. Using Hitachi KLA-3B amino acid analyzer, glucosamine and galactosamine were determined with an acid hydrolyzate $\left(5.6 \mathrm{M} \mathrm{HCl}, 8 \mathrm{hr}, 105^{\circ} \mathrm{C}\right.$ ).

\section{Results and Discussion}

\section{Separation of crude $G A G$ from urine}

The amounts of crude GAG separated from 24-hr urines of 3 patients with Morquio's disease and a normal control are listed in Table 1. The data indicated that large amounts of GAG were excreted into urines of the Morquio's patients.

\section{Separation of keratan sulfate}

The above crude GAG were successively digested with testicular hyaluronidase and chondroitinase $\mathrm{ABC}$ to remove hyaluronic acid, chondroitin, chondroitin sulfates $\mathrm{A}$ and $\mathrm{C}$ and dermatan sulfate, followed by nitrous acid treatment to remove heparan sulfate as described in "Materials and Methods". The resulting fraction containing KS and AGP was then fractionated by Dowex 1 column chromatography. Electrophoretograms on Separax of the resulting fractions showed that KS was not detected in $\mathrm{H}_{2} \mathrm{O} \mathrm{Fr,} 0.5 \mathrm{M} \mathrm{Fr}$ and $1.0 \mathrm{M} \mathrm{Fr}$, but found in other fractions. The distribution of KS in several fractions (1.5 M Fr-5.0 M Fr) suggested polydispersity of urinary KS. Similar finding was observed in a previous paper (Endo et al. 1980b).

Comparison of the KS fractions obtained from Morquio's urine with those from normal urine

Percent yields of the fractions in total obtained by Dowex 1 column chromatography are shown in Fig. 1. The proportions of $2.0 \mathrm{M} \mathrm{Fr}$ and $3.0 \mathrm{M} \mathrm{Fr}$ in total from Morquio's urine significantly increased in comparison with those from normal urine. The sum of the KS fractions (1.5 M Fr-5.0 M Fr) from each patient was listed in Table 1 . The relative amounts $(\mu \mathrm{g} / 24-\mathrm{hr}$ urine $/ \mathrm{kg}$ body weight) of $\mathrm{KS}$

TABLE 1. Amounts of crude $G A G$, ethanol fraction, KS plus $A G P$, and $K S(1.5 M F r-5.0 M$ Fr) separated from urines of the patients with Morquio's disease and of a normal control

\begin{tabular}{|c|c|c|c|c|c|c|c|c|c|}
\hline $\begin{array}{l}\text { Case } \\
\text { No. }\end{array}$ & Patient & Age & Sex & $\begin{array}{c}\text { Body } \\
\text { weight } \\
\text { (kg) }\end{array}$ & $\begin{array}{l}\text { Volume of } \\
\text { 24-urine } \\
\text { (liter) }\end{array}$ & $\begin{array}{l}\text { Crude } \\
\text { GAG }\end{array}$ & $\begin{array}{l}\text { Ethanol } \\
\text { fraction }\end{array}$ & $\mathrm{KS}+\mathrm{AGP}$ & $\frac{\mathrm{KS}}{(1.5 \mathrm{M} \mathrm{Fr}-5.0 \mathrm{M} \mathrm{Fr})}$ \\
\hline 1 & J.S. & 17 & $\mathbf{F}$ & 26 & 1.20 & $760^{*}$ & $286^{*}$ & $102^{*}$ & $24.3^{*}(935) \dagger(52) \ddagger$ \\
\hline 2 & K.M. & 14 & $\mathbf{F}$ & 24 & 1.05 & 558 & 326 & 118 & $25.7(1071) \quad(60)$ \\
\hline 3 & M.A. & 10 & $\mathbf{M}$ & 23 & 1.10 & 405 & 201 & 74 & $25.9(1126) \quad(63)$ \\
\hline Control & & 14 & M & 42 & 1.50 & 23 & 13 & 6 & $0.76 \quad(18)$ \\
\hline
\end{tabular}




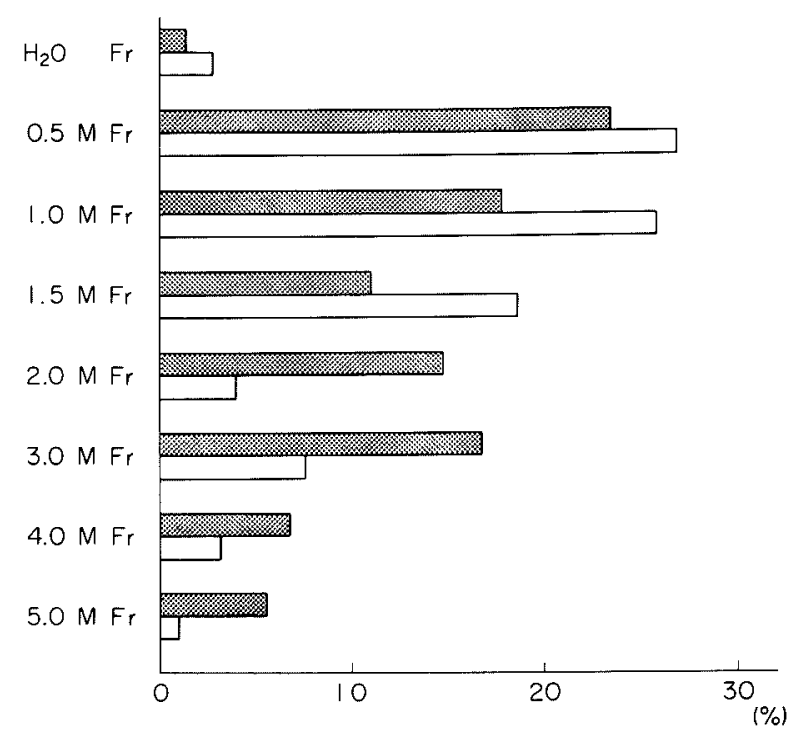

Fig. 1. Percent yields of the fractions in total obtained by Dowex 1 column chromatography of the fractions containing KS and AGP from Morquio's urine of Case 2 (dark bar) and from normal urine (white bar).

excreted into Morquio's urines were 52-63 times as much as that into normal urine. Increased excretion of KS into urine was reported to be a specific figure of Morquio's disease (Dorfman and Matalon 1976).

Representative electrophoretograms of the KS fractions are shown in Fig. 2. All the fractions from Morquio's urine migrated faster in $0.1 \mathrm{M} \mathrm{HCl}$ than the corresponding ones from normal urine (Fig. 2-c), indicating that the sulfate content of each KS fraction from the former was higher than that of the corresponding one from the latter.

The results of the paper chromatography on the acid hydrolyzates of these fractions showed that galactose and glucosamine were contained as the major constituent monosaccharides, together with a fair amount of galactosamine and small amounts of mannose, L-fucose and glucose. Analytical data for the KS fractions are listed in Table 2. The KS fractions resembled sulfated glycopeptide with respect to the sugar composition (Yosizawa 1972). The molar ratios of hexose to hexosamine were similar in all the fractions. The ratio of glucosamine to galactosamine was lower in the fraction eluted at lower $\mathrm{NaCl}$ concentration from Dowex I column than that eluted at higher salt concentration. The sulfate contents in the fractions showed similar trend to the ratios of hexosamines, whereas the opposite was the case for the sialic acid content. On the other hand, the contents of sulfate and sialic acid in each KS fraction from Morquio's urine were higher than those in the corresponding one from normal urine, but the opposite was the case for the ratio of glucosamine to galactosamine. The molar ratios of sulfate to hexosamine in 2.0 M Fr-5.0 M Fr from Morquio's urine were 1.21-1.58, indicating that the patient excreted over-sulfated KS into urine. It is thought therefore 
$A$

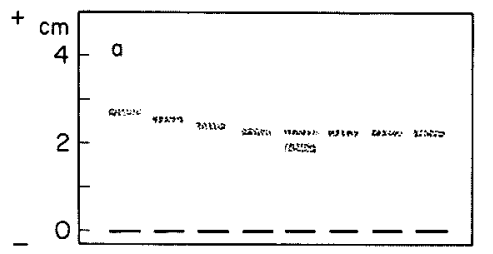

$+\mathrm{cm}$
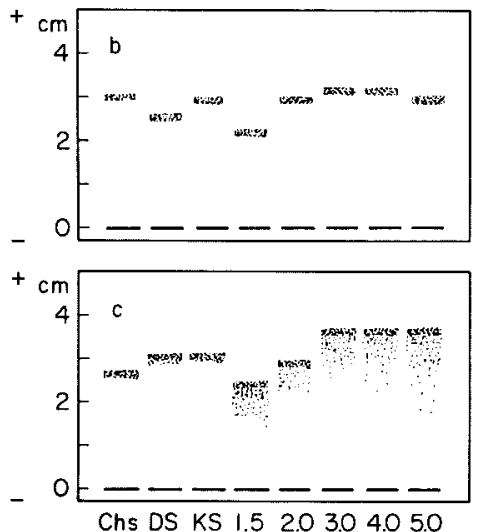

B
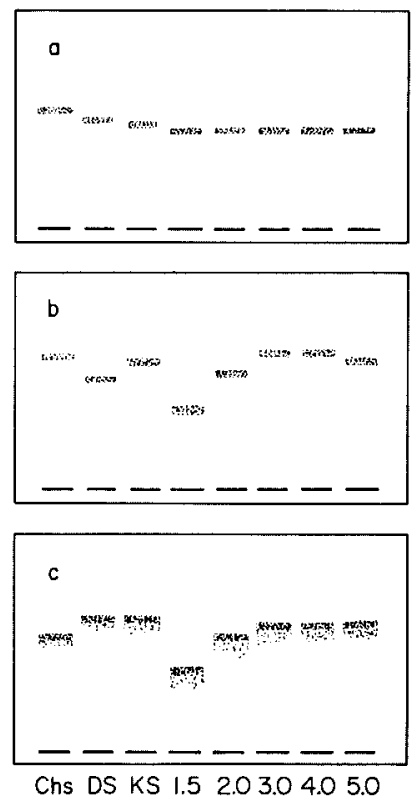

Fig. 2. Tracing of electrophoretograms on Separax (cellulose acetate membrane) of the KS fractions obtained by Dowex 1 column chromatography of the fractions containing KS and AGP from Morquio's urine of Case 2 (A) and from normal urine (B), in formic acid-pyridine buffer ( $\mathrm{pH} 3.0$ ) at $0.5 \mathrm{~mA} / \mathrm{cm}$ for $40 \mathrm{~min}$ (a), in $0.2 \mathrm{M}$ calcium acetate at $0.5 \mathrm{~mA} / \mathrm{cm}$ for $3 \mathrm{hr}(\mathrm{b})$, and in $0.1 \mathrm{M} \mathrm{HCl}$ at $0.5 \mathrm{~mA} / \mathrm{cm}$ for $3 \mathrm{hr}$ (c), stained with Toluidine blue $(0.05 \%$ in $80 \%$ ethanol). Chs, Chondroitin sulfate A; DS, dermatan sulfate; KS, keratan sulfate; 1.5, $1.5 \mathrm{M} \mathrm{Fr} ; 2.0,2.0 \mathrm{M} \mathrm{Fr} ; 3.0,3.0 \mathrm{M} \mathrm{Fr} ; 4.0,4.0 \mathrm{M}$ Fr; 5.0, 5.0 M Fr.

TABLE 2. Analytical data for KS fractions isolated from urines of a patient (Case 2) with Morquio's disease $(M)$ and of a normal control $(C)$

\begin{tabular}{|c|c|c|c|c|c|}
\hline Fraction & & $\begin{array}{c}\text { Hexosamine } \\
\text { (as glucosamine) }\end{array}$ & $\begin{array}{c}\text { Hexose } \\
\text { (as galactose) }\end{array}$ & $\begin{array}{c}\text { Sialic acid } \\
\text { (as N-acetyl- } \\
\text { neuraminic acid) }\end{array}$ & Sulfate \\
\hline $1.5 \mathrm{M} \mathrm{Fr}$ & $\begin{array}{l}\mathrm{M} \\
\mathrm{C}\end{array}$ & $\begin{array}{l}25.4(1.00) *(69.2 / 30.8) \dagger \\
24.0(1.00) \\
(75.4 / 24.6)\end{array}$ & $\begin{array}{l}30.5(1.20)^{*} \\
27.2(1.13)\end{array}$ & $\begin{array}{l}12.4(0.28)^{*} \\
12.3(0.30)^{*}\end{array}$ & $\begin{array}{l}9.9(0.88)^{*} \\
9.3(0.87)\end{array}$ \\
\hline $2.0 \mathrm{M} \mathrm{Fr}$ & $\begin{array}{l}M \\
\mathrm{C}\end{array}$ & $\begin{array}{ll}26.4(1.00) & (79.7 / 20.3) \\
25.4(1.00) & (85.1 / 14.9)\end{array}$ & $\begin{array}{l}32.2(1.22) \\
29.7(1.16)\end{array}$ & $\begin{array}{r}11.3(0.25) \\
9.3(0.21)\end{array}$ & $\begin{array}{l}14.2(1.21) \\
11.0(0.97)\end{array}$ \\
\hline $3.0 \mathrm{M} \mathrm{Fr}$ & $\begin{array}{l}\mathrm{M} \\
\mathrm{C}\end{array}$ & $\begin{array}{l}26.1(1.00) \\
25.8(1.00)(84.7 / 15.3) \\
(86.2 / 13.8)\end{array}$ & $\begin{array}{l}30.8(1.18) \\
31.4(1.21)\end{array}$ & $\begin{array}{r}10.1(0.23) \\
6.1(0.14)\end{array}$ & $\begin{array}{l}16.4(1.41) \\
13.0(1.13)\end{array}$ \\
\hline $4.0 \mathrm{M} \mathrm{Fr}$ & $\begin{array}{l}\mathrm{M} \\
\mathrm{C}\end{array}$ & $\begin{array}{ll}26.7(1.00) & (88.9 / 11.1) \\
24.3(1.00) & (90.0 / 10.0)\end{array}$ & $\begin{array}{l}32.6(1.21) \\
29.2(1.19)\end{array}$ & $\begin{array}{l}8.9(0.19) \\
5.4(0.13)\end{array}$ & $\begin{array}{l}18.8(1.58) \\
12.9(1.18)\end{array}$ \\
\hline $5.0 \mathrm{M} \mathrm{Fr}$ & $\begin{array}{l}\mathrm{M} \\
\mathrm{C}\end{array}$ & $\begin{array}{ll}26.0(1.00) & (91.8 / 9.2) \\
25.6(1.00) & (91.1 / 8.9)\end{array}$ & $\begin{array}{l}30.7(1.18) \\
31.7(1.23)\end{array}$ & $\begin{array}{l}6.2(0.14) \\
6.4(0.14)\end{array}$ & $\begin{array}{l}15.9(1.37) \\
11.7(1.02)\end{array}$ \\
\hline
\end{tabular}

Figures are in $\mathrm{mg}$ per $100 \mathrm{mg}$ of the fraction.

* Molar ratios to hexosamine.

$\dagger$ Percent ratios of glucosamine to galactosamine. 
that over-sulfated KS in the tissues is excreted into urine without desulfation of the galactose 6-sulfate residues in Morquio's disease.

The chemical compositions of the present urinary KS fractions from Morquio's urine were similar to those of the $\mathrm{KS}$ fractions isolated from whale cartilage (Seno 1970). Since tissue KS has been thought to be excreted into urine without significant degradation in Morquio's disease, this observation suggests that human tissue KS resembles whale tissue KS with respect to the chemical compositions, although precise chemical nature of human $\mathrm{KS}$ in the normal tissues remained to be elucidated.

The above observations suggest that the sulfatase specific for 6 -sulfate linked to sugars with galactose configuration may act in a early step of the catabolism of over-sulfated $\mathrm{KS}$ in the normal tissues.

\section{Acknowledgment}

We thank to Dr. M.B. Mathews for supplying standard GAG.

\section{References}

1) Antonopoulos, C.A. (1962) A modification for the determination of sulphate in mucopolysaccharides by the benzidine method. Acta chem. scand., 16, 1521-1522.

2) Bitter, T. \& Muir, H.M. (1962) A modified uronic acid carbazole reaction. Analyt. Biochem., 4, 330-334.

3) Blix, G. (1948) The determination of hexosamines according to Elson and Morgan. Acta chem. scand., 2, 467-473.

4) Dorfman, A. \& Matalon, R. (1976) The mucopolysaccharidoses (a review). Proc. nat. Acad. Sci. USA, 73, 630-637.

5) Duobis, M., Gilles, K.A., Hamilton, J.K., Rebers, P.A. \& Smith, F. (1956) Colorimetric method for determination of sugars and related substances. Analyt. Chem., $28,350-356$.

6) Endo, M. \& Yosizawa, Z. (1973) Hormonal effect on glycoproteins and glycosaminoglycans in rabbit uteri. Arch. Biochem. Biophys., 156, 397-403.

7) Endo, M. \& Yosizawa, Z. (1975) Glycosaminoglycans and acidic glycoproteins in rabbit uterus under estrogenic conditions. Biochim. biophys. Acta, 404, 275-280.

8) Endo, M., Namiki, O. \& Yosizawa, Z. (1974a) Excretion of glycosaminoglycans and glycoproteins in normal human urine with age. Tohoku J. exp. Med., 113, 65-75.

9) Endo, M., Yamamoto, R., Yosizawa, Z., Sasai, Y. \& Saito, N. (1974b) Urinary chondroitin of epidermolysis bullosa dystrophica et albo-papuloidea (Pasini). Clin. chim. Acta, 57, 249-253.

10) Endo, M., Yamamoto, R., Namiki, O., Satake, S. \& Yosizawa, Z. (1979) Comparison of glycosaminoglycans (GAG) in normal human plasma and urine. Tohoku J. exp. Med., 128, 89-99.

11) Endo, M., Namiki, O., Munakata, H. \& Yosizawa, Z. (1980a) Heterogeneity of human urinary glycosaminoglycans. Tohoku J. exp. Med., 131, 167-175.

12) Endo, M., Namiki, O. \& Yosizawa, Z. (1980b) Polydispersity of glycosaminoglycans in normal human urine. Tohoku J. exp. Med., 131, 327-337.

13) Horwitz, A.L. \& Dorfman, A. (1978) The enzymic defect in Morquio's disease: The specificity of N-acetylhexosamine sulfatases. Biochem. biophys. Res. Commun., 80, 819-825.

14) Meyer, K., Davidson, E., Linker, A. \& Hoffman, P. (1956) The acid mucopolysaccharides of connective tissue. Biochim. biophys. Acta, 21, 506-518. 
15) McKusick, V.A. (1972) Heritable disorders of connective tissue. 4th ed., Mosby, St. Louis

16) Rapport, M.M., Meyer, K. \& Linker, A. (1951) Analysis of the products formed on hydrolysis of hyaluronic acid by testicular hyaluronidase. J. Amer. chem. Soc., 73, 2416-2420.

17) Seno, N. (1970) Keratan sulfate of hyaline cartilage. Connective Tissue, 2, 1-9 (in Japanese with English abstract).

18) Warren, L. (1959) The thiobarbituric acid assay of sialic acids. J. biol. Chem., 234, 1971-1975.

19) Yamagata, T., Saito, H., Habuchi, O. \& Suzuki, S. (1968) Purification and properties of bacterial chondroitinases and chondrosulfatases. $J$. biol. Chem., 243, 1523-1535.

20) Yosizawa, Z. (1972) Sulfated glycoproteins. In: Glycoproteins edited by A. Gottschalk, Elsevier Publishing Co., Amsterdam-London-New York, pp. 1000-1018. 